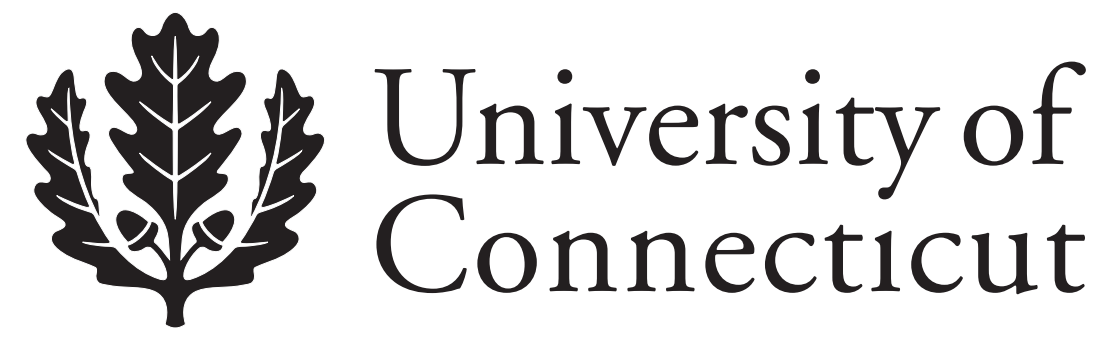

Department of Economics Working Paper Series

Efficiency Rents: A New Theory of the Natural Vacancy Rate for Rental Housing

Thomas J. Miceli

University of Connecticut

C. F. Sirmans

Florida State University

Working Paper 2010-30

November 2010

341 Mansfield Road, Unit 1063

Storrs, CT 06269-1063

Phone: (860) 486-3022

Fax: (860) 486-4463

http://www.econ.uconn.edu/

This working paper is indexed on RePEc, http://repec.org/ 


\begin{abstract}
This paper adapts the theory of efficiency wages to explain the natural vacancy rate in rental housing markets. An equilibrium vacancy rate penalizes landlords who fail to maintain their units because if a tenant vacates a unit, the landlord will not be able to fill it immediately, thus costing him the rental income for a finite period of time. We provide evidence for the theory by showing that vacancy rates across metropolitan areas vary inversely with the stringency of state habitability laws. We also find some evidence for the search-cost theory of the natural vacancy rate.
\end{abstract}

Journal of Economic Literature Classification: K11, R31

Keywords: Efficiency rents, natural vacancy rate, rental housing 


\section{Efficiency Rents: \\ A New Theory of the Natural Vacancy Rate for Rental Housing}

\section{Introduction}

Economists studying the rental housing market often argue that there exists a "natural" vacancy rate that, like the natural unemployment rate, persists because of imperfections in the price adjustment process. ${ }^{1}$ Theoretical explanations for this phenomenon have primarily focused on renter search costs, which prevent the instantaneous adjustment of rents (Read, 1991; Wheaton, 1990; Guasch and Marshall, 1985). Similar arguments have been used to explain the existence of involuntary unemployment in the labor market.

An alternative strand of literature in the labor market context, however, has emerged to offer a different kind of explanation for equilibrium unemployment. These so-called "efficiencywage" models of the labor market contend that wages remain above the market-clearing level because cuts in wages would result in higher costs and/or lower worker productivity (Akerlof and Yellen, 1986). In one version of this argument, Shapiro and Stiglitz (1984) argue that equilibrium unemployment gives workers an incentive to work hard because if they are caught shirking and are fired, they will not immediately be able to find another job and hence will suffer a financial penalty.

This paper adapts the Shapiro-Stiglitz model to the rental housing context by suggesting that an equilibrium vacancy rate similarly imposes costs on landlords who fail to maintain their units in a habitable state. The reason is that, if a sitting tenant detects the undermaintenance and vacates the unit, the offending landlord will not immediately find a replacement tenant and will therefore forego the rental income for a finite period of time. We do not propose this "efficiency-

\footnotetext{
${ }^{1}$ For empirical analyses of the natural vacancy rate, see Eubank and Sirmans (1979), Rosen and Smith (1983), and Gabriel and Nothhaft (2001).
} 
rent" theory as a replacement for search-cost explanations of equilibrium vacancies (any more than efficiency wage models are meant to supplant labor search models), but rather as a complement to it.

In addition to contributing to the theoretical literature on vacancy rates, this paper offers some preliminary empirical evidence in support of the theory. Such a test is possible because in the 1960's and '70s, several states passed laws aimed at inducing landlords to maintain their units in a habitable state (Rabin, 1984; Hirsch, 1988, Chapter 3). To the extent that these laws are effective, market punishment for non-complying landlords through the vacancy rate becomes less necessary. The laws thus allow the market to move closer to the full-occupancy equilibrium. And because these laws vary by state, we are able to ask whether the equilibrium vacancy rate is lower in those jurisdictions with more stringent laws, as the model predicts. Using data from the 1970's, we find evidence in support of this conjecture. Interestingly, we also find evidence for the search-cost model, thus supporting the complementarity of the two explanations for the persistence of equilibrium vacancy rates.

\section{The Model}

The model to be developed in this section is a straightforward adaption of the Shapiro and Stiglitz (1984) model to the rental housing context. Suppose there are $N$ landlords, each of whom offers a single unit for rent. If the landlord succeeds in renting out his unit during a given period, he earns a market-determined rent of $R$, whereas if the unit remains vacant, he earns nothing. In each period that the unit is occupied, the landlord must decide whether or not to 
invest in maintenance at a cost of $m$. The function of maintenance is to maintain a certain level of housing quality by offsetting the usual wear and tear associated depreciation. ${ }^{2}$

At the end of each period, sitting tenants will vacate their units for exogenous reasons (e.g., job relocation) with probability $a$, regardless of whether or not the landlord invested in maintenance. In addition, a tenant who otherwise planned to stay will vacate with probability $b$ if the landlord did not invest in maintenance. This reflects the reaction of tenants who value a certain level of housing quality and are willing (or able) to move when the landlords fails to maintain that level. The overall probability that a sitting tenant will vacate his or her unit is therefore $a$ if the landlord invests in maintenance, and $a+b$ if he does not.

The possibility of losing a tenant, with the resulting foregone rent, is one means of ensuring landlord maintenance, but, as noted above, there may also be legal sanctions. Changes in landlord-tenant laws during the mid-twentieth century imposed on landlords a legal duty to maintain their buildings in a "habitable" condition. ${ }^{3}$ Failure to do so generally results in some sort of monetary sanction in the form of damages (possibly through withholding of rent) and/or fines. To capture the disciplinary function of these habitability laws, we assume that landlords who fail to invest in maintenance in a given period, in addition to possibly losing their tenants, face an expected financial liability of $L$.

In any given period, the landlord either has a tenant or he does not. If he has a tenant, he decides whether or not to invest in maintenance. In a steady-state equilibrium, a landlord will either always or never find it optimal to invest, depending on which offers the higher present value of profits. Thus, define $\Pi_{m}^{t}$ to be the present value of the landlord's expected profits if he

\footnotetext{
${ }^{2}$ We ignore the impact of tenant maintenance in offsetting depreciation (see Miceli, 1992), as well as the possibility of excessive tenant utilization resulting from the rental externality (Henderson and Ioannides, 1983).

${ }^{3}$ See, for example, Pines v. Perrsion, 14 Wis. 2d 590, 111 N.W.2d 404 (1961); and Javins v. First National Realty Corp. 138 U.S. App. D.C. 369, 423 F.2d 1071, cert. denied, 400 U.S. 925 (1970). Also see the discussion in Hirsch (1988, Chapter 3) and Rabin (1984).
} 
always invests, and define $\Pi_{0}^{t}$ to be the corresponding expression for a landlord who never invests. Also, define $\Pi^{v}$ to be the present value of expected profits for a landlord with a vacant unit (to be derived below).

Given the above assumptions, we can write

$$
\Pi_{m}^{t}=R-m+\frac{1}{1+r}\left[a \Pi^{v}+(1-a) \Pi_{m}^{t}\right],
$$

and

$$
\Pi_{0}^{t}=R-L+\frac{1}{1+r}\left[(a+b) \Pi_{0}^{t}+(1-a-b) \Pi^{v}\right] .
$$

Equations (1) and (2) can be used to derive the condition for a landlord to find it profitable to invest in maintenance, or $\Pi_{m}^{t} \geq \Pi_{0}^{t}$. The result is

$$
R \geq \frac{(a+b+r)}{b} m-\frac{a+r}{b} L+\frac{r}{1+r} \Pi^{v} .
$$

This condition, which we assume must hold in equilibrium, puts a lower bound on the equilibrium rent.

To derive an expression for $\Pi^{v}$, assume that a landlord with a vacant unit expects to find a tenant for the next period with probability $q$, which the landlord takes as given, but which will be determined in equilibrium. We further assume that the landlord must invest in maintenance of the vacant unit in order to have a chance of attracting a tenant—-that is, landlords who do not maintain their units will have no chance of attracting a tenant. ${ }^{4}$ Given that (3) holds (implying that landlords with tenants will invest in maintenance), the present value of profit from a vacant unit is

$$
\Pi^{v}=-m+\frac{1}{1+r}\left[q \Pi_{m}^{t}+(1-q) \Pi^{v}\right] .
$$

Solving this equation simultaneously with (1) yields the reduced form expressions

\footnotetext{
${ }^{4}$ This assumption is inessential for the basic results.
} 


$$
\begin{aligned}
& \Pi_{m}^{t}=\frac{(1+r)(r+q)}{r(a+r+q)} R-\frac{1+r}{r} m, \\
& \Pi^{v}=\frac{(1+r) q}{r(a+r+q)} R-\frac{1+r}{r} m .
\end{aligned}
$$

Substituting (6) into (3) yields the reduced form condition for the landlord to invest in maintenance:

$$
R \geq \frac{(a+r+q)}{b}(m-L) \equiv \hat{R}
$$

where $\hat{R}$ is the minimum rent necessary to induce maintenance.

It is important to emphasize that rent can serve as an enforcement mechanism in this model because landlords who fail to maintain their units are more likely to lose their tenants, which results in a loss of rental income during the time that the unit sits vacant. It follows from

(7) that $\hat{R}$ is increasing in (i) the cost of maintenance $(m)$, (ii) the exogenous probability that the tenant will vacate the unit (a), (iii) the probability that the landlord will fill a vacant unit $(q)$, and (iv) the interest rate $(r)$. Conversely, the minimum rent is decreasing in (i) the probability that a tenant will vacate the unit when the landlord fails to maintain it $(b)$, and (ii) the legal liability for failing to maintain the unit in a habitable state $(L)$.

\subsection{Market equilibrium}

To this point, we have considered the incentives of individual landlords to invest in maintenance, taking as given both the equilibrium rent and the probability that a landlord with a vacant unit will be able to fill it. Both of these variables, however, will be determined in equilibrium. We assumed above that the supply of rental units is fixed at $N$. We now define $Q(R)$ to be the demand for maintained units, where $Q^{\prime}<0$. In a market where maintenance incentives are not an issue, the equilibrium rent would be determined by the equation $Q(R)=N$. 
The resulting "full occupancy" rent, $R^{*}$, is shown in Figure 1, where the downward sloping curve is the inverse demand function, $R(Q)$. In this case, the vacancy rate would obviously be zero, and landlords would fill vacancies with certainty in each period; that is, $q^{*}=1$.

The problem with this outcome is that $R^{*}$ may not satisfy (7), in which case landlords would not have an incentive to maintain their units. The possibility that $R$ may need to be above $R^{*}$, resulting in an excess supply of units, is what provides the link between landlords' maintenance and the vacancy rate. Define the vacancy rate in the current model to be

$$
v=\frac{N-Q}{N}
$$

Thus, $v=0$ at $R^{*}$ by definition. We can now relate the parameter $q$, the probability that a vacant unit will be filled, to the vacancy rate by recognizing that in a steady-state equilibrium, the number of tenants who exogenously leave their apartments each period, $a Q,{ }^{5}$ must equal the number of vacant units that are filled, $q(N-Q)$, or

$$
q=\frac{a Q}{N-Q}
$$

Substituting this expression into (7) for $q$ yields

$$
R \geq \frac{m-L}{b}\left(a+\frac{a Q}{N-Q}+r\right)
$$

or, after simplifying and using (8),

$$
R \geq \frac{m-L}{b}\left(\frac{a}{v}+r\right) \equiv \hat{R}
$$

According to this condition, the minimum rent the landlord must receive in order to find it profitable to invest in maintenance is inversely related to the vacancy rate. It follows from (10) that there is no finite rent that can induce maintenance if $v=0$. Intuitively, as it becomes easier

\footnotetext{
${ }^{5}$ Note that since landlords invest in maintenance in equilibrium, tenants only vacate for exogenous reasons.
} 
for a landlord to fill a vacant unit, the cost of losing a tenant in terms of foregone rent falls. Thus, the landlord has less incentive to invest.

Figure 2 graphs $\hat{R}$ as a function of $Q$. Note that it is positively sloped (given that $\frac{\partial v}{\partial Q}<0$ from (8)) with an intercept of

$$
\hat{R}(0)=\frac{m-L}{b}(a+r)
$$

Also note that $\hat{R}$ is asymptotic to the fixed supply curve at $N$. This reflects the fact that as $Q$, the number of renters successfully finding an apartment, approaches $N$, the vacancy rate goes to zero, which, as noted above, is not consistent with landlord maintenance. The equilibrium is shown by the intersection of the $\hat{R}$ locus with the inverse demand curve, yielding an equilibrium rent of $R^{e}$ and an equilibrium vacancy rate of $v^{e}=\left(N-Q^{e}\right) / N$.

\subsection{Comparative Statics}

Differentiating the right-hand side of (10) with respect to $L$ yields

$$
\frac{\partial \hat{R}}{\partial L}=-\frac{1}{b}\left(\frac{a}{v}+r\right)<0
$$

Thus, an increase in the legal sanction for failing to maintain a unit in a habitable state causes the minimum rent locus to shift down, as shown by the dashed curve in Figure 2. As a result, both the equilibrium rent and the number of vacant units fall. Intuitively, as external enforcement of the landlord's duty to maintain the unit is strengthened, there is less need for market enforcement, so the market equilibrium more closely approaches the full-occupancy outcome. This result provides the basis for a test of the theory, to be presented in the next section.

It also follows from (10) that the minimum rent is decreasing in $b$, the probability that a tenant will vacate when the landlord fails to invest in maintenance. This reflects the fact that as tenants are better able to detect or respond to a landlord's failure to maintain, the deviation of the rent from the full-occupancy level can be smaller. In contrast, the minimum rent is increasing in 
$a$, the exogenous probability that a tenant will vacate. This is true because exogenously triggered vacancies lessen the impact of intentional vacancies aimed at punishing the landlord. Finally, the minimum rent is increasing in the interest rate since a higher $r$ implies that the landlord places a lower value on future losses.

\section{Some Evidence}

A full test of the above theory is beyond the scope of this paper, but it is possible to offer some preliminary evidence based on the predicted inverse relationship, shown in (12), between the equilibrium vacancy rate and the stringency of legal sanctions for failing to maintain a unit in a habitable state. The vacancy rate data to be used in the analysis were obtained from Rosen and Smith (1983), who estimated the natural vacancy rate for fifteen metropolitan areas using data from 1969 to $1980 .{ }^{6}$ They defined the natural vacancy rate as follows: "The optimal or natural vacancy rate in any market can be defined as that rate at which there is no excess demand nor excess supply and hence the rent is in its long-run equilibrium” (Rosen and Smith, 1983, p. 782). Their calculation of this rate, obtained by estimating rent adjustment equations, yielded estimates ranging from 6.0 (New York) to 23.2 (Milwaukee), with a mean of 11.45 and a standard deviation of 4.60 .

For the legal variable we constructed an index of habitability laws from data collected by Hirsch during the years $1974-1975,{ }^{7}$ a time frame that closely corresponds to the period of the Rosen and Smith (1983) estimates. The index reflects the presence or absence of four different

\footnotetext{
${ }^{6}$ The cities were Baltimore, Boston, Chicago, Cincinnati, Cleveland, Dallas, Denver, Houston, Kansas City, Los Angeles, Milwaukee, Minneapolis, New York, Pittsburgh, and St. Louis.

${ }^{7}$ See Hirsch (1981). The actual data are provided in Hirsch (1988, p. 75). An advantage of using Hirsch's index rather than more recent data, in addition to saving on the data collection costs, is that there is considerable variation in the law during this earlier period, given the differential initial response of states to the judicial mandate. As time passes, however, laws tend to become more uniform.
} 
types of laws aimed at holding landlords legally responsible for maintaining their units in a habitable state. These laws are (1) repair and deduct laws, which allow tenants to undertake their own maintenance and then deduct the cost from their rent; (1) rent withholding laws, which allow tenants to withhold payment of rent until defects are repaired; (3) receiverships laws, which allow the court to appoint a receiver to take control of a building for purposes of correcting defects; and (4) anti-retaliation laws, which protect tenants from retaliation for reporting violations by the landlord. Hirsch used a dummy variable to denote the presence $(=1)$ or absence $(=0)$ of each type of law in a given state. To economize on degrees of freedom, we collapsed the laws into a single index equal to the sum of the dummies across the four types of laws. The index thus ranges from 0 to 4 , (where a higher index indicates more stringent laws) with a mean of 2.33 and a standard deviation of 1.5. Obviously, we keyed the metropolitan areas to the relevant states to determine the appropriate index.

A scatter plot of the data, shown in Figure 3, reveals a clear negative relationship between vacancy rates and the law index, as predicted by the model. If we exclude the Milwaukee outlier (as Smith and Rosen did in their analysis of the cross-sectional determinants of the natural vacancy rate), the negative correlation is even more pronounced. (The correlation coefficient is -.47 with Milwaukee and -.79 without.)

Table 1 presents the results of an OLS regression of the vacancy rate on the law index with the outlier included (column 1) and with it excluded (column 2). In both cases the coefficient on the law index is negative and significant, at the $10 \%$ level in the first case and the $1 \%$ level in the second. Columns 3-5 report the results of several multiple regressions that include various combinations of the variables used by Rosen and Smith (1983) in their crosssectional analysis. (The Milwaukee outlier is excluded from all of these regressions.) These 
variables include the renter mobility rate from 1975-1980, the change in the housing stock from 1970-1980, and the dispersion in rents as measured by the standard deviation. We obtained all of these data from the 1980 Census. Of these additional variables, only the mobility rate is significant (at the $10 \%$ level using a one-tailed test), suggesting that states with more mobile renters have higher vacancy rates. Note that this result is consistent with the search-cost theory of equilibrium vacancy rates. More importantly for our purposes is that the law index remains negative and significant at the 5\% level in all of the specifications, thus providing strong support for the efficiency rent theory as a complementary explanation for the natural vacancy rate.

\section{Conclusion}

This paper proposed a new theory of the natural vacancy rate for rental housing based on insights gained from efficiency wage models of the unemployment rate. The idea is that a positive vacancy rate provides an incentive for landlords to invest in maintenance of their buildings because if they fail to do so, some tenants will vacate, and the unit will sit vacant for some finite period of time. The resulting foregone rent will then serve as a penalty for the landlord's failure to maintain. The argument is intended to complement rather than replace existing theories of persistent vacancy based on tenant search costs.

The paper also provided a test of the theory based on the existence of state-level habitability laws that threaten legal sanctions against landlords who fail to maintain their buildings. Since legal sanctions are a substitute for market discipline, the model predicted that those states with more stringent laws should have lower vacancy rates. Using data on estimated vacancy rates from the 1970s and an index of state habitability laws from the same time period, we found a significant negative relationship as predicted by the model. We also found that 
mobility of renters had a positive effect on vacancy, as predicted by conventional search-cost models. Our empirical analysis thus reflects the complementarity of these two explanations for persistent vacancy rates in the rental housing market. 


\section{References}

Akerlof, G. and J. Yellen (1986) Efficiency Wage Models of the Labor Market, Cambridge: Cambridge Univ. Press.

Eubank, A. and C.F. Sirmans (1979) "The Price Adjustment Mechanism for Rental Housing in the United States," Quarterly Journal of Economics 93: 163-193.

Gabriel, S. and F. Nothaft (2001) "Rental Housing Markets, the Incidence and Duration of Vacancy, and the Natural Vacancy Rate," Journal of Urban Economics 49: 121-149.

Guasch, J. and R. Marshall (1985) "An Analysis of Vacancy Patterns in the Rental Housing Market," Journal of Urban Economics 17: 208-229.

Hirsch, W. (1988) Law and Economics, $2^{\text {nd }}$ Edition, Boston: Academic Press. (1981) "Habitability Laws and the Welfare of Indigent Tenants," Review of Economics and Statistics 63: 263-274.

Miceli, T. (1992) "Habitability Laws for Rental Housing: The Impact of Tenant Laws," Urban Studies 29: 15-24.

Rabin, E. (1984) "The Revolution in Residential Landlord-Tenant Law: Causes and Consequences," Cornell Law Review 69: 517-584.

Read, C. (1991) "A Price Dispersion Equilibrium in a Spatially Differentiated Housing Market with Search Costs," AREUEA Journal 19: 532-547.

Rosen, K. and L. Smith (1983) "The Price-Adjustment Process for Rental Housing and the Natural Vacancy Rate,” American Economic Review 73: 779-786.

Shapiro, C. and J. Stiglitz (1984) "Equilibrium Unemployment as a Worker Discipline Device," American Economic Review 74: 433-444.

Wheaton, W. (1990) "Vacancy, Search, and Prices in a Housing Market Matching Model," Journal of Political Economy 98: 1270-1292. 
Table 1. Regression of natural vacancy rate on habitability law index.

\begin{tabular}{lccccc}
\hline Variable & $(1)$ & $(2)$ & $(3)$ & $(4)$ & $(5)$ \\
\hline Law index & $-1.445^{*}$ & $-1.739^{* * *}$ & $-1.266^{* *}$ & $-1.646^{* *}$ & $-1.301^{* *}$ \\
& $(1.922)$ & $(4.534)$ & $(2.817)$ & $(2.413)$ & $(2.303)$ \\
& & & & & \\
Mobility Rate & -- & -- & $12.418^{*}$ & $12.672^{*}$ & $12.368^{*}$ \\
$\quad(1975-80)$ & & & $(1.717)$ & $(1.618)$ & $(1.500)$ \\
Change in Housing & -- & -- & -- & -0.743 & 0.899 \\
$\quad$ Stock (1970-80) & & & & $(0.129)$ & $(0.115)$ \\
Rent Dispersion & -- & -- & -- & -- & 0.060 \\
& & & & & $(0.329)$ \\
Constant & $14.824 * * *$ & $14.589 * * *$ & $8.485^{* *}$ & $8.480^{* *}$ & 9.901 \\
& $(7.185)$ & $(13.958)$ & $(2.303)$ & $(3.862)$ & $(1.672)$ \\
$n$ & 15 & 14 & 14 & 14 & 14 \\
$\bar{R}^{2}$ & .161 & .601 & .657 & .623 & .586 \\
\hline
\end{tabular}

Note: Absolute values of $t$-statistics in parentheses.

$* * *$ denotes significance at the $1 \%$ level.

$* *$ denotes significance at the $5 \%$ level.

$*$ denotes significance at the $10 \%$ level. 


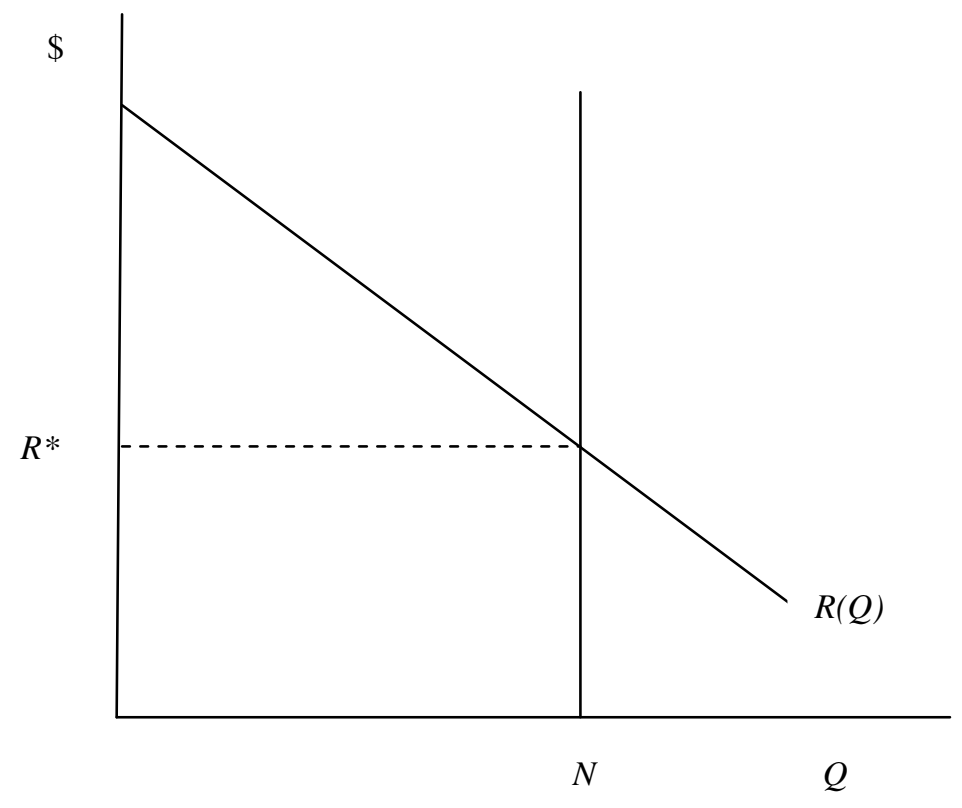

Figure 1. Full occupancy equilibrium. 


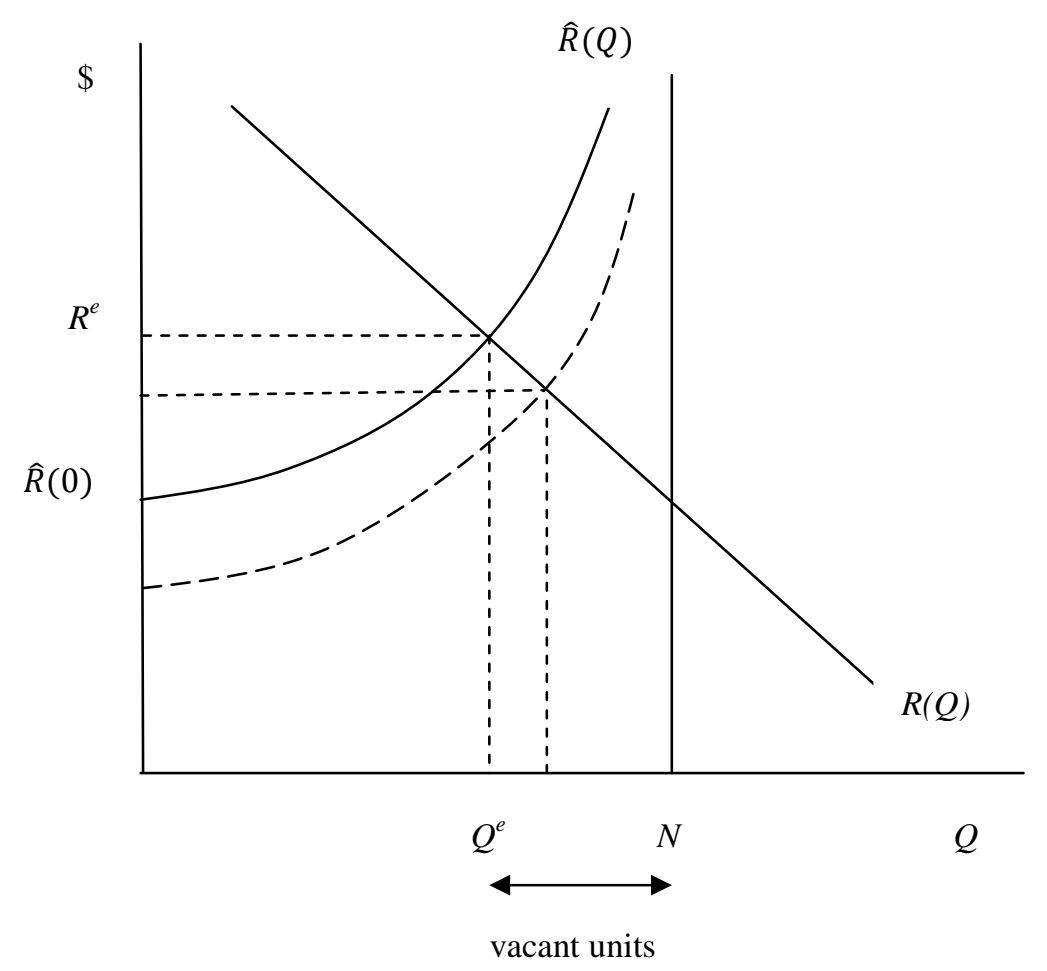

Figure 2. Equilibrium efficiency rent and number of vacant units. 


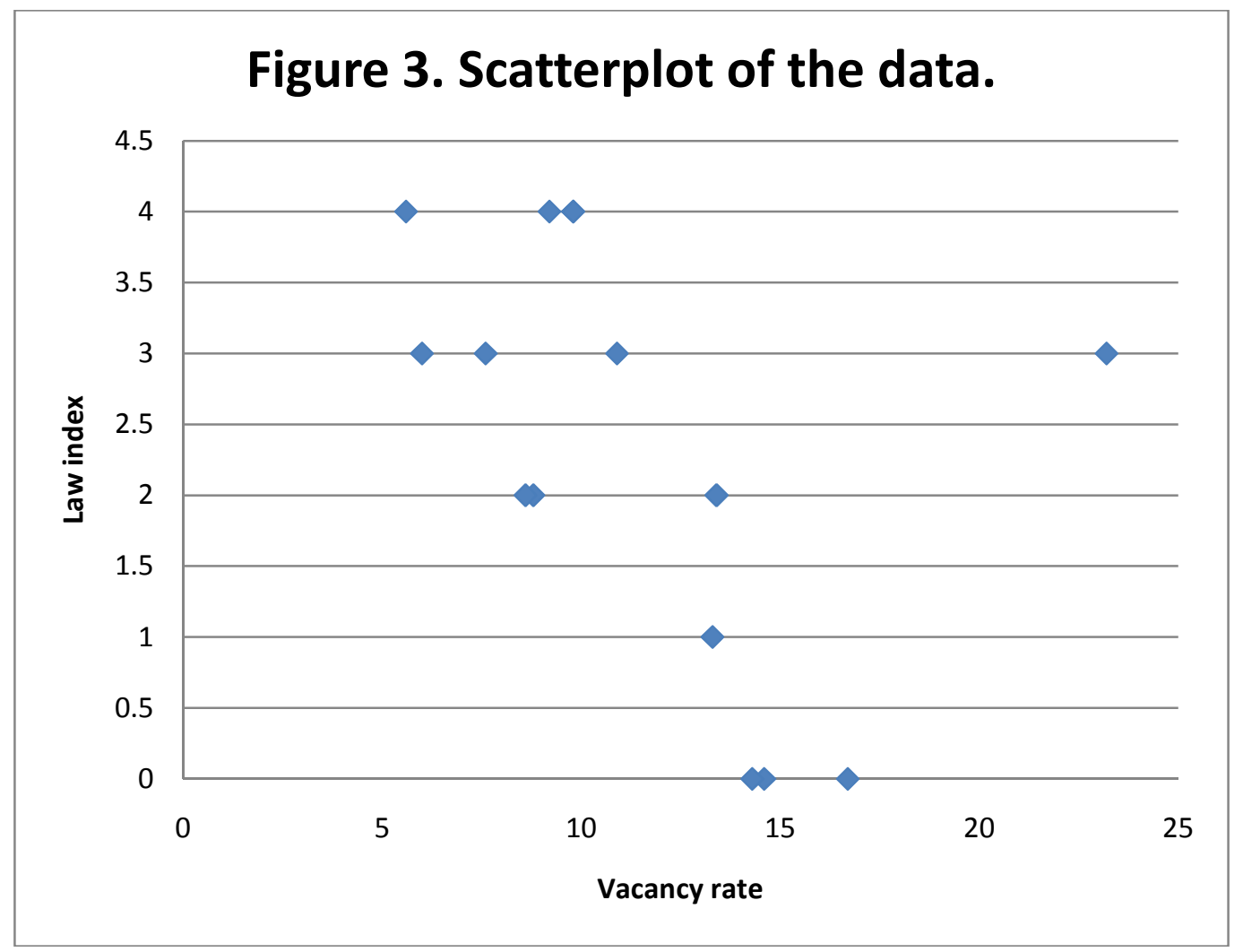

